\title{
A análise de discurso como abordagem metodológica nas Relações Internacionais: a influência do Discurso de Segurança Humana na Política Externa Japonesa'
}

\author{
Discourse Analysis as methodological approach \\ in International Relations: the influence of the Human \\ Security Discourse in the Japanese Foreign Policy
}

Aline Chianca Dantas* Alexandre César Cunha Leite**

\section{Resumo}

O presente artigo debate o uso do método de análise de discurso nas Relações Internacionais por meio de uma breve análise do discurso de segurança humana na política externa japonesa, seguindo a compreensão de discurso de Foucault e Pêcheux e as etapas de análise apontadas por Fairclough.

Palavras-chave: Análise de discurso, Metodologia e Teoria de Relações Internacionais, Discurso de segurança humana japonês.

\section{Abstract}

This article discusses the use of discourse analysis method in International Relations through a brief discourse analysis of human security in Japan's foreign policy, following the understanding of discourse from Foucault and Pêcheux and the analytical steps outlined by Fairclough.

Keywords: Discourse analysis. Methodology and Theory of International Relations. Japanese Human Security Discourse.

1 Os autores agradecem os comentários e as observações feitos pela Prof. ${ }^{a}$ Dra. Ana Paula Maielo Silva e pelo Prof. Dr. Cristiano Garcia Mendes, os quais foram fundamentais para o aprofundamento teórico do artigo, isentando-os, todavia, de qualquer responsabilidade pelo conteúdo nele desenvolvido.

* Doutoranda em Relações Internacionais pela Universidade de Brasília

** Doutor em Ciências Sociais/Relações Internacionais (PUC/SP). Professor Adjunto de Relações Internacionais da Universidade Estadual da Paraíba - UEPB 


\section{Introdução}

O estudo aqui abordado tem como foco debater como a utilização da metodologia de pesquisa, denominada de análise de discurso, tem sido desenvolvida no âmbito das Relações Internacionais. Para isso, observa-se o uso do método da análise de discurso nas abordagens consideradas pós-positivistas, especialmente construtivistas, pós-modernistas, pós-estruturalistas e pós-colonialistas. Assim, são apresentados breves apontamentos de autores associados a essas linhas teóricas que trabalham com discurso, tais como Onuf (2002), Zehfuss (2002) e George (1994), com intuito de revelar a importância desses trabalhos, muitas vezes, deixados à margem no âmbito das Relações Internacionais, seja pela dificuldade do estudo ou pelas críticas na confiabilidade do método. Ademais, o presente trabalho apresenta uma abordagem prática da análise de discurso nas Relações Internacionais com objetivo de aprofundar as discussões à luz da percepção prático-teórica.

Dessa maneira, inicia-se o artigo apresentando o que se compreende por discurso à luz de Foucault $(1986,1996,2010)$ e Pêcheux (1997, 2007), que representam a corrente de análise de discurso francesa, a qual é de grande valia para os debates presentes nesse artigo, juntamente com a abordagem da Análise Crítica do Discurso, que será mais utilizada na segunda parte do artigo, embora ambas pertençam historicamente a ramos distintos da linguagem, como bem asseveram Resende e Ramalho (2006, p. 21). 0 uso, no entanto, dessas duas abordagens se justifica pelo fato de os estudos de Foucault serem reconhecidamente fundamentais no que concerne ao discurso e às relações de poder (FAIRCLOUGH, 2001, p. 61-62) e o artigo que se desenvolve tem como cerne revelar os interesses e relações de poder que estão por trás dos discursos dentro do ambiente das Relações Internacionais e, mais especificamente, da política externa japonesa, por meio do caso prático apresentado.

Já a abordagem de Fairclough (2001, p. 100-101) é trazida para o trabalho, em virtude de utilizar-se de fases para a análise discursiva, que se mostram relevantes para a análise de discurso que aqui se desenvolve, pois conseguem abarcar a observação do texto, a evolução ao longo do tempo, a percepção da produção e distribuição do discurso, os fatores históricos envolvidos e a reflexão sobre a própria análise empreendida, questões essas que são importantes para a estruturação de uma análise de discurso e uma possivel replicação da mesma para verificação de resultados. Em seguida, discutem-se os pressupostos, os objetivos, o roteiro de estudo e os autores relevantes no que tange à análise do discurso, compreendendo-se um pouco mais esse método analítico.

Após esse conhecimento prévio, passa-se ao delineamento da relação entre a análise de discurso e o campo das Relações Internacionais, percebendo o uso feito pelas correntes teóricas da área do método da análise de discurso e apresentando exemplos de estudos de caso associados ao referido instrumento analítico, com a finalidade de revelar as regularidades e problemáticas em torno da abordagem discursiva.

Por fim, chega-se ao momento prático da utilização da metodologia de análise do discurso, cujo foco traduz-se em apreender a relação entre o discurso de segurança humana japonês e a política externa do referido país; assim, apresenta-se uma evolução da concepção do discurso dentro da política japonesa e são ressaltados alguns discursos políticos, nos quais a segurança 
humana aparece; desse modo, busca-se aqui deflagrar as nuances que se encontram por trás do discurso e as externalidades que se conectam a ele. A referida análise será feita de maneira breve, sem visar a esgotar os debates sobre o tema, ressaltando a forma e as limitações da própria análise, possibilitando que novas pesquisas sejam feitas com o mesmo método, dentro do mesmo campo e diferentes resultados sejam alcançados. Nesses termos, utiliza-se o método de análise de discurso crítico de Fairclough (1996, p. 24-25; 2001, p. 100-101) - análise do texto, percepção da prática discursiva, observação do discurso enquanto prática social - e as abordagens de Foucault (1986, 1996, 2010) e Pêcheux (1997, 2007), que tratam do discurso, sua produção e seus efeitos.

O intuito dessa análise prática é, além de mostrar a aplicabilidade da metodologia para o caso trabalhado, servir também de motivação para incitar produções na área de Relações Internacionais ligadas à análise de discurso, aprimorando, assim, o uso desse método dentro do citado campo teórico. Ademais, pretende-se referendar como a supracitada abordagem metodológica pode ser utilizada e qual a sua importância, considerando o caso concreto do discurso de segurança humana no Estado japonês.

Portanto, o que se busca demonstrar é que, individualmente, todo método de análise e abordagem teórica são incapazes de analisar um objeto por completo, em decorrência das variáveis envolvidas e da complexidade das interações existentes em um determinado cenário. Assim, para cada caso, tem-se a possibilidade de utilizar diversos métodos, dentre eles a análise de discurso, que tem uma característica bastante interessante, ou seja, apresentar a significação das palavras, dos atos e dos gestos associados ao contexto externo da prática social e à figura que profere o discurso, permitindo a compreensão da conjuntura, já que o discurso é resultado do meio e consequência dele.

\section{O Discurso e a análise discursiva como instrumental metodológico}

Antes de ingressar no campo das Relações Internacionais, é pertinente detalhar mais o que vem a ser discurso, qual o seu papel, os interesses que estão no seu entorno, compreender em que se consubstancia o método da análise de discurso, observando sua especificidade e de que maneira ele é trabalhado aqui, bem como as diferentes correntes, tendências e fases de análise de discurso.

Então, conforme Foucault (1996, p. 8-9), a produção do discurso é controlada, selecionada, organizada, redistribuída, visa a dominar uma materialidade e conspirar poderes e perigos. Por isso, a forte crítica que o autor atribui ao discurso verdadeiro e às imbricações entre o discurso e as relações de poder. Em Arqueologia do Saber, Foucault (1986) visa a construir, para além de uma teoria, mas também um método didático, que objetiva compreender o funcionamento dos discursos que constituem as ciências humanas. Em um rompimento com a formulação estruturalista², Foucault (1986, p. 47) sugere que o discurso representa um conjunto de práticas discursivas que instauram objetos sobre os quais enunciam, tangenciam, delimitam conceitos

2 Principalmente aqueles tributários do pensamento estruturado por Saussure (REVEL, 2005). 
e, acima de tudo, de fundamental relevância para o texto que se constrói aqui, legitimam os sujeitos enunciadores e fixam estratégias.

É válido ponderar que Foucault (1986, p. 43) estabelece ainda uma noção de discurso que o restringe ao tempo e ao espaço, destinando-se a uma determinada área "social, econômica, geográfica ou linguística, considerando as condições de exercício da função enunciativa". Dessa maneira, vê-se a importância de dois grandes fatores para a análise de discurso, tempo e espaço, que são instrumentos essenciais para o bom desenvolvimento do método, como se poderá observar nos casos práticos apresentados e no estudo em torno do discurso de segurança humana na política externa japonesa que aqui se desenvolve.

Assim, Gondim e Fischer (2009, p. 13) pontuam que, para Foucault, o discurso constitui um conjunto de acontecimentos que o coloca na dimensão histórica e se materializa na linguagem por meio de enunciados e cabe ao analista de discurso desvendar as regras da formação discursiva e ter acessibilidade às condições de existência que lhes dão sentido. Complementando essa ideia, Orlandi (2005, p. 11) assevera que, para Pêcheux, o discurso é "um efeito de sentidos entre locutores, um objeto sócio-histórico em que o linguístico está pressuposto", com isso Pêcheux critica o sentido evidente do discurso.

Em Michel Pêcheux (2007, p. 21), observa-se a argumentação de que o discurso deve ser pensado considerando-se sua íntima ligação com as condições de produção; ao "analisar um discurso como um texto", faz-se necessário "referi-lo ao conjunto dos discursos possíveis, a partir de um estado definido de condições de produção".

O interessante do discurso é que, embora pareça ser brando ou não surtir tantos efeitos, ele consegue ser institucionalizado e legitimado sem, muitas vezes, ser percebido (FOUCAULT, 1996, p. 6-7). Assim, Foucault (1996, p. 49) assevera que "discurso nada mais é do que a reverberação de uma verdade nascendo diante de seus próprios olhos". O discurso, então, é narrado conforme circunstâncias determinadas e possui limitações advindas do autor, dos comentários e do aporte disciplinar para o qual é voltado, logo, observa-se a necessidade da crítica da análise do discurso (FOUCAULT, 1996, p. 63 e 69).

Nesses termos, Nicholas Onuf (2002, p. 119), pensando o discurso e sua análise dentro do campo das Relações Internacionais, discute as diversas verdades existentes nos vários mundos e mostra a relevância do agente para a mudança da estrutura ou de sua manutenção, utilizandose do discurso para tal feito. Ademais, como versa o autor, o discurso promove a diminuição dos mundos que somos coletivamente capazes de identificar; assim, o olhar do observador torna o mundo o que ele quer ver. Acrescenta-se ainda que o discurso e seus derivados são meios de construção social e a pessoa se torna agente dentro de um mundo de linguagem (ONUF, 2002, p. 124 e 127). A língua, a linguagem e o discurso modificam o meio, as regras e o próprio homem, mas o efeito também ocorre de maneira inversa, formando o eterno círculo interacional entre agentes, regras e estrutura, difundido por Onuf (2002, p. 129).

É válido realçar que os discursos possuem em si conteúdo normativo, dessa forma, os atores criam constrangimentos na ordem das normas para si próprios e para os que estão em seu entorno, por meio dos atos da fala (ZEHFUSS, 2002, p. 171). Um ponto crítico apresentado por Maja Zehfuss (2002, p. 180-183) em relação à visão de Onuf é que nem sempre o discurso promove a mudança da realidade, então, alguns discursos têm mais força que outros e isso 
é consequência das relações de poder. Nesse sentido, pode existir, por exemplo, um discurso normativo na Constituição de um país, mas a prática revela a prevalência de um outro discurso que conseguiu se sobressair, tornando o trecho constitucional válido, vigente e ineficaz, porque não produz efeitos no mundo real, levando inclusive a possíveis mudanças no discurso normativo do texto constitucional.

Ainda no que tange ao discurso, Pinto (2006, p. 80-82) o considera como uma provisória fixação de sentido, ressaltando que a verdade é uma construção discursiva, logo, o sentido do discurso é delimitado de maneira arbitrária, pois nada assegura que o sentido deveria ser obrigatoriamente o que é. Sendo assim, a autora citada ressalta que o discurso contém significados incorporados por sujeitos que os constroem ou são por eles sujeitados, além de provocarem efeitos concretos na forma das pessoas se relacionarem e nos rumos da história (PINTO, 2006, p. 82).

É essencial também ilustrar os delineamentos de Suano (2005, p. 270) de que os discursos dos representantes dos atores configuram a produção de doutrinas, que, por sua vez, consubstanciam-se na congregação e aplicação de teorias. Isso é bem considerável quando se pensa, por exemplo, em política externa de um determinado país, como será debatido mais à frente.

Considerando os aspectos apresentados, o que seria então, a análise de discurso? Por esta se entende o processo de abandono da concepção de discurso como categoria pré-estabelecida (WITTCENSTEIN apud GONDIM e FISCHER, 2009, p. 11), constituindo-se em uma teoria ou método de estudo do próprio discurso por intermédio de vários campos disciplinares, como a linguística, o materialismo histórico e a psicanálise (FERNADES; ORLANDI apud GONDIM e FISCHER, 2009, p. 11). Assim, com a análise de discurso visa-se a percepção das condições de produção social, histórica e ideológica do discurso (GONDIM e FISCHER, 2009, p. 12).

O surgimento da Análise de Discurso dá-se na década de 1960 na França e tem como base o materialismo histórico, o estruturalismo e a linguística, mas carrega como especificidade o fato de valorizar a relação entre as condições histórico-sociais de produção do discurso e seus processos de constituição, que levam à produção de determinados sentidos. Nesses termos, apesar da existência de um ponto em comum, podem-se apresentar diferentes análises de discurso. Então, existem duas raízes de análise de discurso e com elas diferentes tendências, sendo uma francesa, a qual delibera que os sujeitos são condicionados por uma determinada ideologia que predetermina o que podem ou não dizer em certa conjuntura histórico-social, e a outra denominada de análise de discurso anglo-saxã ou americana, que se pauta na intenção dos sujeitos numa interação verbal (MUSSALIM, 2006, p. 111-113).

São apontadas pela literatura diferentes fases da Análise de Discurso (AD). A AD1, que tem um caráter mais positivista e se estrutura com base na análise de discursos mais estabilizados, como os políticos teórico-doutrinários, exemplificados pelo Manifesto Comunista, sendo essa corrente fundamentada no conceito de máquina discursiva, ou seja, uma estrutura estável é geradora de um processo discursivo, a partir de argumentos estanques; a AD2, por sua vez, trabalha com a concepção de formação discursiva, que é o conjunto de regras históricas, determinadas no tempo e no espaço que impactam na função enunciativa. Essa perspectiva de análise se embasa nas ideias de Foucault e Pêcheux e é uma das principais abordagens 
desse artigo, juntamente com a Análise Crítica do Discurso que se detalha em seguida. Por fim, fala-se da AD3, que é uma abordagem pós-estruturalista, focada no conceito de interdiscursividade, isto é, na relação entre discursos. Tal abordagem aparece no texto por meio de autores como Hansen e Zehfuss, mas não é o cerne dos debates e das discussões sobre o método da análise de discurso (MUSSALIM, 2006, p. 117-119).

Ainda é possível falar na vertente da Análise Crítica do Discurso que aparece na década de 1970 e se distancia dos conceitos e bases da Análise de Discurso apresentada acima, preocupando-se em trabalhar o discurso como prática social, numa percepção do discurso como ligado à dominação e às relações de poder. Essa abordagem possui uma base marxista forte e tem origem nos estudos anglo-saxônicos. Nesse trabalho, dá-se ênfase às ideias de um dos autores basilares para essa corrente que é Fairclough, o qual analisa o discurso enquanto instrumento de mudança social como um acréscimo à Análise de Discurso já discutida (MELO, 2009, p. 9, 12-13). Essa perspectiva de análise é utilizada aqui em virtude das etapas consideradas por Fairclough na análise de discurso e da tentativa de debater como o discurso de segurança humana japonês pode promover mudanças sociais e do próprio caráter do Japão, de maneira implícita.

Nessas condições, privilegia-se nesse trabalho, além da Análise de Discurso francesa, a Análise Crítica do Discurso, que se pauta pela compreensão linguística, crítica-social e sócio-histórica (TILIO, 2010, p. 86). Por conseguinte, de acordo com Chouliaraki e Fairclough apud Tilio (2010, p. 87), a Análise Crítica do Discurso seria um método de análise das práticas sociais com preocupação notória para as situações discursivas que ligam questões teóricas e práticas às esferas públicas, nas quais as formas de análise se operacionalizam, tornando-se, então, práticas e possibilitando teorizações sobre o discurso na vida social e, a partir da análise de discurso, tem-se a possibilidade de desenvolvimento e elaboração dessas teorias.

É imprescindivel nesse momento apresentar dois modelos de análise de discurso, o primeiro parte da concepção tridimensional do discurso de Fairclough (1996, p. 24-25; 2001, p. 100-102, 106-107), que são: análise de texto (preocupações formais do texto com fins interpretativos e de percepção dos processos produtivos), prática discursiva (produção, distribuição e consumo do texto) e discurso como prática social (processos anteriores ao texto e que têm impacto sobre ele, baseados nas relações socialmente construídas). Já o segundo modelo, de Chouliaraki e Fairclough (1999, p. 60), possui as seguintes etapas: percepção do problema (conexão entre discurso e relações de poder), análise dos obstáculos a serem ultrapassados (conjuntura), função do problema na prática (relação entre texto e prática social), superação dos problemas (propostas de mudanças) e, finalmente, a reflexão sobre o próprio ato de análise (GOMES, 2011, p. 664-667). Nesse trabalho, essas abordagens discursivas são utilizadas para a análise do caso concreto da relação entre o discurso de segurança humana e a política externa japonesa.

Por fim, é fundamental diferenciar a análise de discurso da análise de conteúdo; pois, na primeira, observa-se um detalhamento da questão ideológica do discurso e, na segunda, deflagra-se um processo de simples compreensão do teor do texto, sem pensar nas ideologias construídas e nas formas de visualizar o mundo (GONDIM e FISCHER, 2009, p. 12-13). Portanto, a análise de discurso é mais complexa e permite realmente a compreensão de uma conjuntura. 


\section{Análise de discurso no campo das Relações Internacionais}

Os estudos de análise de discurso nas Relações Internacionais aparecem dentro das abordagens pós-positivistas e algumas delas são brevemente apresentadas aqui. Assim, objetiva-se mostrar a relevância desses estudos dentro do arcabouço teórico das Relações Internacionais, bem como as problemáticas que os envolvem, com fulcro de incentivar produções que possuam esse tipo de análise.

Conforme Comes (2011, p. 675), a análise de discurso nas Relações Internacionais é decorrente do movimento denominado Virada Linguística, por meio do qual se buscava afastar a concepção de que a linguagem era puro reflexo das condições materiais e ideacionais da sociedade, pois a linguagem, como já foi ressaltado, interfere nos diversos mundos que estão em volta do indivíduo. Assim, é através da análise de discurso francesa que esse método ingressa no âmbito das Relações Internacionais, especialmente, por meio das figuras de Foucault e Pêcheux e com base nos seguintes pensamentos: a língua possui uma ordem própria, mas é relativamente autônoma, a história é afetada pelo simbólico e o sujeito da linguagem é assujeitado (ORLANDI apud GOMES, 2011, p. 646).

De acordo com Camargo (2011, p. 94), a análise de discurso surgiu nas Relações Internacionais nas décadas de 1980 e 1990, com o terceiro debate entre realistas e neorrealistas e as abordagens pós-positivistas. Isso é fruto da tentativa de mudança dos parâmetros metodológicos por parte das teorias pós-positivistas, que queriam romper com as ideias rígidas e deterministas das abordagens anteriores, revelando diferentes formas de análise de um mesmo objeto de estudo e, até mesmo, criticando a própria forma como as teorias positivistas também representavam discursos de poder que, até então, eram vistos como verdadeiros.

O grande problema é que a análise de discurso é um método ainda marginalizado nas Relações Internacionais (CAMARG0, 2011, p. 94). Desse modo, tem-se que:

O estudo do discurso interpela diversas correntes das Relações Internacionais como o pós-estruturalismo, o feminismo e o construtivismo social, mas apresenta nuances, conceitos e posicionamentos díspares entre elas e dentro delas. Apesar das diferentes reflexões produzidas por essas correntes acerca do estudo do discurso, elas convergem em um único feixe: a marginalização da linguagem nos estudos de Relações Internacionais (CAMARGO, 2011, p. 95).

No que tange aos construtivistas, Camargo (2011, p. 95) afirma que não houve preocupação com os métodos e critérios de análise de discurso nas Relações Internacionais, em virtude de as primeiras abordagens construtivistas, em geral, estarem preocupadas com a aceitabilidade de suas ideias dentro do campo das Relações Internacionais, que era predominantemente positivista. Assim, percebeu-se o surgimento de abordagens mais abrangentes, mas que não necessariamente rompiam totalmente com as anteriores. Já Onuf (2002, p. 131-133), dentro de uma linha mais crítica do construtivismo, argumenta que o construtivismo é importante porque fomenta a sensibilidade para a linguagem enquanto instrumento de ação, por promover uma abertura metodológica e considerar os processos sociais e as regras como essenciais. 
Assim, o trabalho de Onuf (2002) configura uma grande referência nos estudos de discurso dentro do âmbito das Relações Internacionais e no que tange às abordagens construtivistas. Da mesma forma, Zehfuss (2002), partindo de premissas ainda mais críticas, utiliza as teorias construtivistas, compreendendo as relações de normas e discursos à luz do caso prático do envolvimento militar alemão no meio internacional.

Diante das abordagens construtivistas expostas, é pertinente ressaltar a existência de diferentes construtivismos e, por consequência, distintos focos de análise em relação aos elementos constitutivos das Relações Internacionais, embora todas carreguem consigo a crítica às abordagens realistas tradicionais.

Quanto aos estudos pós-estruturalistas, Hansen (2006) declina que existe uma relação entre identidade, política externa e discurso, sendo este um conjunto de fatores ideacionais e materiais. Os discursos políticos, dessa forma, estão associados à produção e reprodução de subjetividades e identidades particulares em detrimento de outras excluídas (HANSEN, 2006). A identidade está no centro ontológico e epistemológico da análise de discurso pós-estruturalista e tem como característica ser constitutiva e produto da política externa de um país (HANSEN, 2006).

Ainda dentro da corrente pós-estruturalista, James Der Derrian (1999) expressa a importância de investigar teoricamente a representação roteirizada das Relações Internacionais. Nesse sentido, a estratégia intertextual tem como cerne compreender o lugar e o não lugar das teorias, a superioridade e o silêncio das teorias, a separação entre teoria - prática de conhecimento - dos eventos - práticas inspiradas materialmente (DER DERRIAN, 1999).

Shapiro (1999), por sua vez, mostra a relevância de se verificar os caminhos pelos quais as Relações Internacionais vêm sendo historicamente escritas e interpretadas. De acordo com o autor, existe uma nítida relação entre prática textual e política, tendo em vista que formas privilegiadas de representação passam a ser aceitas, legitimando sujeitos, objetos, atos e temas e construindo o mundo político.

De acordo com Shapiro (1999), o modo de análise dos pós-estruturalistas é centrado no discurso, pois este implica uma preocupação com o significado e as práticas de produção de valor da linguagem. Enquanto esta, por sua vez, está voltada para a relação entre enunciados e seus referenciais. Assim, há o incentivo para a análise das práticas linguísticas.

Também a partir do pensamento de Shapiro (1999), tem-se que as políticas externas dos Estados-nação são baseadas nas práticas representacionais por meio das várias formas de alteridade globais que têm sido criadas, como o conceito de América Latina. Acrescenta ainda o autor que o conceito de segurança pode funcionar como um instrumento de política externa, permitindo a criação de perigos e ameaças, possibilitando a criação de estruturas de autoridade e controle e a explicitação de sujeitos, objetos e relações (SHAPIRO, 1999). O discurso, assim, pode funcionar como legitimador de políticas públicas ou externas (SHAPIRO, 1999, p. 18).

Quanto ao pós-colonialismo, vale frisar os apontamentos trazidos por Niranjana (1992) quando ressalta os delineamentos em torno da tradução, referenciando a importância da linguagem nas relações de conhecimento e poder e reverberando a relevância de repensar os valores, as crenças e as ideologias que se encontram por trás da tradução, pois esta se forma pela arbitrariedade e pela natureza construída, sendo assim, um texto em tradução possui mais de uma linguagem nas suas entrelinhas (NIRANJANA, 1992, p. 153 e 180). 
Segundo preceitua Jim George (1994, p. 156 e 172-173), para a perspectiva pós-moderna, objetos e sujeitos são sociolinguisticamente construídos e seus significados são processos que ocorrem no tempo e no espaço, representando a si mesmos e ao mundo como parte das práticas discursivas. 0 referido autor trata justamente da crítica às percepções teóricas anteriores das Relações Internacionais, que se configuram como construções interessadas, voltadas apenas para as soluções de problemas, sem se preocuparem com as questões sociais, históricas, por meio das quais o discurso teórico é constituído. As ideias de Foucault (2010, p. 5-6) são também incorporadas às discussões pós-modernas nas Relações Internacionais, sobressaltando a estreita relação entre os discursos e as relações de poder.

Diante do exposto, visualizam-se algumas preocupações dentro das Relações Internacionais em torno do discurso e de sua análise. Sendo assim, o método apresentado tem aparecido em estudos sobre política externa, terrorismo e mídia (GOMES, 2011, p. 671 e 672; CAMARG0, 2011, p. 93-100). Camargo (2011, p. 101-103), por exemplo, expressa como a análise de discurso pode ser um método interessante para trabalhar com a mídia. Nesses termos, a autora desenvolve uma abordagem sobre a percepção brasileira em torno da guerra do Iraque de 2003 , por meio dos recortes internacionais dos jornais a Folha de São Paulo, O Estado de São Paulo e O Globo, seguindo uma delimitação temporal. No que tange ao terrorismo, Gomes (2011, p. 671) ressalta que o periódico Critical Studies on Terrorism vem primando por abordagens que tratam do fenômeno pelo viés discursivo.

A análise de discurso, então, se aproxima das abordagens pós-positivistas das Relações Internacionais, especialmente por acentuar, à luz do discurso, questões como identidade, relações de poder, representatividade, interações simbólicas, que são fundamentais para essas perspectivas mais críticas dentro do referido campo de estudo. Observa-se, no entanto, que, apesar de as teorias mais críticas das Relações Internacionais terem aceitado, de alguma maneira, a análise de discurso como método de análise, este uso ainda precisa passar por aprofundamentos metodológicos, a fim de se fazer uma boa utilização do método, retirando dele a maior quantidade de informações possíveis e possibilitando sua replicabilidade, além de ser necessária a sua difusão no campo das Relações Internacionais.

O problema das Relações Internacionais, como um todo, é que os estudos de teoria são limitados (MILLIKEN, 2001, p. 147), sendo mais difícil ainda existir interesse em trabalhar com abordagens bastante criticadas dentro da área, como a análise de discurso. Contudo, Milliken (2001, p. 138-139) afirma que estudos bem refletidos nas Relações Internacionais de análise de discurso podem ser feitos, desde que se orientem por argumentos teóricos, como a percepção de discurso enquanto sistema de significação, o debate sobre a produção discursiva e o jogo da prática, ou seja, entendimento das questões de poder ligadas ao discurso. Assim, a compreensão das situações internacionais é fortalecida por essas análises mais robustas, para além das teorias das Relações Internacionais criadas com intenções explicativas, utilizando-se de métodos e abordagens advindos de outros campos que possam complementar a compreensão do caso concreto, como se observa da análise de discurso.

Conclui-se, portanto, que a falta de consenso na utilização do método da análise de discurso nas Relações Internacionais não deve ser um empecilho para a proliferação de conhecimento por meio dele; por outro lado, deve-se investir em novas pesquisas para testar 
a eficácia do método abordado. Com base nisso, a análise de discurso pode ser utilizada associada às diferentes perspectivas teóricas e aos outros métodos cabíveis, com finalidade de se alcançar pesquisas mais profundas e críticas no âmbito das Relações Internacionais (CAMARGO, 2011, p. 98-100).

\section{A relação entre Segurança Humana e Política Externa Japonesa à luz do instrumental da análise de discurso}

Em conformidade com os debates teóricos apresentados, passa-se ao estudo do caso prático que versa sobre a influência do discurso de segurança humana japonês na política externa do Japão e vice-versa, além dos reflexos para a segurança nacional do país. 0 período de análise escolhido é de 1990 a 2012, que representa o período de ascensão do discurso no cenário japonês. Assim, seguindo os ensinamentos foucaultianos (1996), o discurso de segurança humana japonês pode ser percebido como uma verdade nascida de dentro das esferas políticas competentes diante dos próprios olhos da comunidade nacional e internacional.

Esse processo é decorrente da transformação do discurso de segurança tradicional - que deu ensejo à Segunda Guerra Mundial e a consequências nefastas para o Japão - em direção ao discurso de segurança humana, caracterizado, como explicita Paris (2001), por uma percepção abrangente, abarcando não apenas a violência física contra um ser humano, mas também a violência indireta ou estrutural, que é aquela provocada por questões incorporadas ao sistema, tais quais fome, doenças, problemas no meio ambiente, drogas, dentre outras (SAKURAI, 2011, p. 185 e 193-194).

É relevante apontar que a segurança humana aparece no cenário internacional em 1994, em decorrência do relatório do Programa das Nações Unidas para o Desenvolvimento (OLIVEIRA, 2009), mas no Estado japonês surge e é inserida como elemento de política externa depois, como se verá adiante nas análises dos discursos e na discussão baseada na literatura sobre o tema.

Mas qual a influência desse discurso sobre a política externa japonesa? O que se percebe é que esse discurso dá margem para uma atuação internacional mais ativa, sem confrontar diretamente as normas estabelecidas no âmbito interno e nem afrontar o ambiente internacional com intenções explícitas de busca de poder. Então, deflagra-se um processo de mútuo fortalecimento entre o discurso de segurança humana e a política externa japonesa, bem como da própria segurança nacional do país, mesmo diante do art. $9^{\circ}$ da Constituição Japonesa, que cerceia o uso da força japonesa apenas para fins de defesa³. Contudo, com o discurso de segurança humana, o conceito de defesa torna-se mais amplo, possibilitando a atuação das Forças de Autodefesa Japonesas (equivalente às Forças Armadas em outros países, mas com

3 Uma emenda constitucional foi aprovada em setembro de 2015 garantindo a possibilidade de atuação das Forças de Autodefesa Japonesas em operações militares no exterior, embora haja muito questionamento interno e externo a respeito dessa mudança. Disponivel em: < http://www.aereo.jor.br/2015/09/19/forcas-de-autodefesa-do-japao-agora-podem-realizar-operacoes-militaresno-exterior/ > Acesso em: 22 out. 2015. Essa mudança não invalida a importância do discurso de segurança humana para o Japão, bem como de seu caráter pacifista, pelo contrário, esses elementos são fundamentais para o Japão poder lidar com seu entorno regional em meio a essa medida que claramente avança no sentido da militarização do país. 
características próprias centradas na primazia da defesa) em ambientes internacionais, por meio das operações de manutenção de paz e ajudas a desastres, apesar das restrições do art. $9^{\circ}$ constitucional.

Os discursos políticos esclarecem bem o que se está tentando apresentar, por isso, ressaltar-se-ão alguns discursos em momentos históricos diferentes para que se possa debater a evolução desse discurso ao longo do tempo como elemento da política externa japonesa. A primeira vez em um discurso político 4 no Japão que se fez alusão a um conceito próximo do que se entende por segurança humana foi em 1995 por meio do Primeiro-Ministro Murayama na Assembleia Geral das Nações Unidas (BOSOLD e WERTHES, 2005; FUKUSHIMA, 2004). Conforme Fukushima (2004), em discurso no Encontro Mundial de Desenvolvimento Social em Copenhague no ano de 1995, Murayama assinalou:

....as head of the Japanese government, I seek the creation of a 'human-centered society',
a vision of Japan in which each individual citizen is treated equally, endowed with [the]
opportunity to fully develop his or her potential, and enabled to utilize fully his or her
capacity through employment and participation in society ... Japan gives priority to human-
centered social development. At present, the share of Official Development Assistance (ODA)
allocated to this area already exceeds twenty percent of the total of Japan's bilateral ODA
(MURAYAMA apud FUKUSHIMA, 2004, p. 133).

Em seguida, há referência novamente ao que se compreende por segurança humana no discurso do Primeiro-Ministro Hashimoto em 1997 na Assembleia Geral das Nações Unidas, quando ele ressalta a importância da segurança da humanidade/segurança humana global (BOSOLD e WERTHES, 2005).

A primeira vez, no entanto, que a segurança humana realmente aparece em um discurso político relacionando-se com a política externa japonesa é em 1998, por meio das palavras do Primeiro-Ministro Obuchi ${ }^{5}$. 0 discurso de segurança humana concatenado com a política externa japonesa emerge como estratégia de superação da crise financeira asiática do período, estimulando as estratégias de desenvolvimento (BOSOLD e WERTHES, 2005). No entanto, o discurso de Obuchi voltava-se também para o ambiente nacional (FUKUSHIMA, 2004) e, para ilustrar o apresentado, tem-se o seguinte trecho retirado do discurso do referido PrimeiroMinistro na $145^{\text {a }}$ Sessão da Dieta Nacional, proferido em 19 de janeiro de 1999:

Preserving life and ensuring a safe way of life, which can otherwise be spoken of as ensuring human security, is one more important duty which we bear. I am committed to building a bridge to security until we are able to guarantee the security of every one of our citizens, and to preserve the environment of our climate.

4 É importante frisar que todos os discursos aqui apresentados foram originalmente encontrados na língua inglesa, tendo em vista que são discursos oficiais japoneses feitos na ONU. Embora não seja o foco da análise aqui desenvolvida, para um estudo mais denso em torno da análise de discurso, seria pertinente aprofundar na questão do idioma japonês, suas nuances, construções linguísticas, como são feitas as traduções para o inglês e de que forma isso impacta no discurso político. A iniciativa de análise de discursos em inglês não se invalida, pois o Japão tem grande abertura para o idioma, fornecendo em seus diversos sites oficiais documentos língua inglesa e japonesa.

5 É válido apontar que na década de 1970 e 1980 começou a haver um processo de ampliação do conceito de segurança nacional a fim de reforçar os processos de ajuda externa japonesa, nesse sentido, surgiu o conceito de segurança nacional compreensiva (ARAGUSUKU, 2011), podendo ser vistas conexões com o uso mais recente do discurso de segurança humana. 
Nesse discurso, percebe-se uma visão de segurança humana voltada para um período em que o Japão necessitava ampliar sua inserção na esfera internacional, além de aumentar sua legitimidade nacional e o discurso parecia um bom instrumento para isso.

O Primeiro-Ministro Mori manteve a linha adotada por Obuchi e fixou a segurança humana enquanto elemento de política externa japonesa, isso pode ser claramente visto no seu discurso proferido no ano 2000 na 55ª Sessão da Assembleia Ceral da ONU:

At the dawn of a new century, we are faced with various problems such as conflicts, human rights violations, poverty, infectious diseases, crime and environmental destruction, which threaten the existence and dignity of each and every person. We must deal with these problems from the standpoint of the importance of each individual. This is the concept of human security. With human security as one of the pillars of its diplomacy, Japan will spare no effort to make the twenty-first century a human-centred one. (p. 17)

É válido realçar que o discurso de segurança humana continuou sendo uma política do Estado japonês, embora tenha sido mais ressaltado em alguns momentos em detrimento de outros, tudo isso é possibilitado pela institucionalização da segurança humana enquanto elemento da agenda de política externa japonesa, por meio de diálogos intelectuais e simpósios, diminuindo a necessidade de enfatizar o discurso (FUKUSHIMA, 2004).

No governo do Primeiro-Ministro Koizumi (2001-2006) observou-se uma diminuição do uso do discurso de segurança humana e, ao mesmo tempo, uma mudança de foco, tendo em vista que o discurso passou a se voltar para a legitimação de políticas antiterroristas, reforçando a atuação japonesa no Afeganistão, como pontua Fukushima (2004, p. 141). Disso, percebe-se como o discurso de segurança humana funciona como um elemento estratégico para o governo japonês, sendo um instrumental para o Japão no sentido de possibilitar a contribuição japonesa para a segurança internacional e regional sem interferir nos preceitos antimilitaristas que configuraram as bases do Estado japonês atual (CLAUSEN, 2009).

O próximo pronunciamento político em torno da segurança humana a ser apresentado é do Primeiro-Ministro Hatoyama durante a 64 ${ }^{a}$ Sessão da Assembleia Geral da Organização das Nações Unidas (ONU) em 24 de setembro de 2009. Nele já se percebe de maneira bem nítida os interesses que se encontram por trás do discurso de segurança humana, tais como o aprimoramento da assistência oficial ao desenvolvimento, especialmente na África:

Japan will work in partnership with international organizations and NGOs and strengthen its assistance to developing countries in terms of both quality and quantity. Japan intends to continue and strengthen the Tokyo International Conference on African Development (TICAD) process, and redouble its efforts towards the achievement of the Millennium Development Goals (MDGs) and the promotion of human security.

Diante do referido discurso e em consonância com os ensinamentos de Juliano Aragusuku (2010), vê-se que a assistência oficial ao desenvolvimento possui uma importância política no plano internacional para o Japão, no sentido de suprir lacunas na área de segurança e de aprimorar a reputação japonesa internacionalmente. Ocorre que essas finalidades são implícitas 
e o discurso de segurança humana é relevante para permitir essa dominação simbólica japonesa, mantendo o ar de benevolência e altruísmo das ações do Estado japonês (AKIYAMA apud ARACUSUKU, 2010).

De acordo com o Primeiro-Ministro Naoto Kan em discurso na 65ª Sessão da Assembleia Geral da Organização das Nações Unidas em 2010, vê-se a relação entre segurança humana e operações de paz, revelando os interesses japoneses de inserção internacional por meio desse tipo de atividade: "Japan will make efforts to advance this seamless approach to peacebuilding in the world, based on the perspective of human security".

Finalmente, ilustra-se o discurso envolvendo a segurança humana do Primeiro-Ministro Noda na 67 ${ }^{a}$ Sessão da Assembleia Geral das Nações Unidas no dia 26 de setembro de 2012, conforme o qual se deflagra a conexão do discurso com a presença do Japão na África e no Oriente Médio, além da atuação japonesa em operações de manutenção de paz, que são promovidas pelas Forças de Autodefesa Japonesas:

\begin{abstract}
We must completely resolve challenges that place our precious lives in danger. Afghanistan is making its utmost efforts for reconstruction after the long-drawn scourge of war, South Sudan is advancing its nation-building efforts, and Myanmar has taken steady steps toward democracy and reconciliation. Japan will make every possible effort to support and promote peacekeeping, peacebuilding, and "human security" in each region.
\end{abstract}

Dos discursos expostos, verifica-se o constatado por Fukushima (2004, p. 155), de que o Japão introduziu a segurança humana na sua política externa com intuito de criar várias políticas voltadas para o controle da crise econômica de 1997 e depois esse discurso tornou-se um caminho para o Japão avançar na contribuição da paz e segurança, por meio do Fundo Fiduciário de Segurança Humana e da Assistência Oficial ao Desenvolvimento - ODA.

Dessa forma, embora o discurso de segurança humana pareça uma simples retórica, como todo discurso, tem um objetivo e um autor interessado por trás, no caso em tela, o Estado japonês. Ademais, a emergência do discurso de segurança humana japonês pode ser pensada como uma tentativa de emancipação do Japão (B00TH, 1991; IKEDA, 2009). Aqui se vê o motivo da produção do discurso de segurança humana e quem está promovendo o referido discurso, como se pode retirar das etapas de análise de discurso de Fairclough (2001, p. 106-107), por meio da análise da prática discursiva, e de Foucault (1996) e Pêcheux (1997), considerando as preocupações com a produção discursiva e as relações de poder.

Nesses termos, Akami (2006) questiona a real efetividade do discurso de segurança humana, pois delineia que a noção abrangente de segurança do povo já foi usada como justificativa para a guerra. Assim, aponta que, desde 1945, a segurança do povo tem sido parte da política japonesa como uma "retórica" dentro de um contexto imperialista. Então, observa-se que há um objetivo sim por trás do discurso de segurança humana japonês, mas ele não coincide necessariamente com o interesse altruísta encontrado na definição de segurança humana abrangente. Nesse trecho, apresenta-se uma reflexão sobre a terceira etapa de Fairclough (1996, p. 24-25), ou seja, o discurso como prática social, demonstrando como processos anteriores são relevantes no estudo do discurso e na interação com a sociedade, pontuando como o interesse 
e as relações de poder influenciam na construção do discurso e na sua difusão e, ainda, de que maneira um mesmo discurso, baseado na mesma premissa de concretização do interesse estatal, pode ser utilizado em contextos distintos, levando a diferentes resultados, mas revelando a tênue proximidade entre os efeitos do discurso.

Por outro lado, Atanassova-Cornelis (2005), discutindo a ação proativa do Japão e a perspectiva de interligação entre a segurança humana e o papel multilateral nos assuntos de paz e estabilidade, ressalva que a segurança humana, como um dos aspectos da política externa japonesa, tem sido implementada na prática pelas políticas japonesas e atividades pós-conflito, ensaiando, assim, uma visão positiva do Estado japonês, sua política externa e do discurso de segurança humana. Esse ponto ilustra uma reflexão sobre a análise referendada no trabalho, explicitando que existem outras formas de se enxergar a discussão empreendida, embora não seja a que se defende no trabalho; assim, passa-se por uma etapa fundamental, acrescentada pelo pensamento de Chouliaraki e Fairclough (1999, p. 60).

Contudo, independente dos debates sobre aplicabilidade ou não do discurso de segurança humana, estrutura-se de forma contundente a compreensão de Caterina Segura (2006-2007) de que o conceito de segurança humana é um instrumento que responde à necessidade do governo japonês de dar respostas às pressões externas e internas de renovação de uma política externa reativa e de baixo perfil sem alterar os elementos políticos, sobre os quais uma reforma pode implicar em reações negativas dos vizinhos asiáticos e da própria opinião pública.

Dessa maneira, observa-se o quão importante é o discurso de segurança humana para o Estado japonês, enquanto elemento discursivo e estratégico, possibilitando a ligação do país com o povo e com o meio internacional, além do reforço da atuação das próprias Forças de Autodefesa japonesas legitimadas pelo discurso ${ }^{6}$. Então, seguindo os passos de Fairclough (1996, p. 24-26; 2001, p. 100-101) - análise do texto discursivo, da produção, distribuição e consumo textual e do discurso como prática social, ou seja, percepção de processos anteriores que impactam o texto e as relações texto-sociedade -, buscou-se desenvolver uma breve análise do discurso de segurança humana como influenciador e influenciado pela política externa japonesa e a segurança nacional do país.

Portanto, o primeiro passo na análise do caso concreto constitui-se na observação dos textos e de sua evolução ao longo do tempo, relacionando o discurso de segurança humana com outros fatores relevantes para a política externa japonesa e a segurança nacional do país, como a assistência oficial ao desenvolvimento e a atuação das Forças de Autodefesa em operações de manutenção de paz. Em seguida, parte-se para um exame da produção e distribuição do discurso de segurança humana, respaldando a discussão na forma como o Estado japonês produz o discurso e o utiliza no meio interno e internacional, a fim de angariar legitimidade, já que a segurança humana permite um olhar inicial positivo sobre as ações do governo japonês,

6 É fundamental apontar que não se está aqui sugerindo uma ligação natural de causa e efeito entre o discurso de segurança humana e a atuação das Forças de Autodefesa Japonesas no âmbito internacional, até porque legislação específica do país permitiu isso e no ano de 2015 mudanças constitucionais reforçaram, apenas se está ressaltando a importância desse discurso como instrumental da política externa japonesa e possivel ferramenta facilitadora da atuação dessas forças no sistema internacional e fortalecedora da imagem pacifista japonesa mesmo em meio a avanços militaristas. 
por aproximar o Estado de uma preocupação humanitária e social, embora a prática não necessariamente coincida com a teoria do discurso pregado.

Também se reflete sobre o uso do referido discurso de segurança humana em período anterior ao que se analisa nesse estudo, demonstrando a apropriação do Estado feita do discurso de modo a legitimar a segurança do povo em meio à guerra, situação essa que parece fortalecer o fato de o discurso estar funcionando como um instrumento do Estado japonês, com finalidade de possibilitar sua expansão, seja em termos militares na segurança nacional japonesa, seja em questão de prestígio e poder nas relações internacionais. Por último, realça-se a preocupação com a reflexão da própria análise depreendida, ressaltando que existem distintos pontos de vista sobre a temática e que outros estudos e análises mais profundos devem ser realizados a fim de demonstrar o direcionamento dado ao discurso de segurança humana japonês, sua efetividade prática e os impactos disso para o Estado japonês.

\section{Conclusão}

Diante do exposto, conclui-se que a análise de discurso pode ser um método relevante para realizar trabalhos que envolvam percepções, relações e processos, pois tem a capacidade de revelar as entrelinhas que levaram à produção da prática discursiva e ainda ensejar debates sobre a influência desse discurso dentro do ambiente social. Tudo isso, compreendendo discurso não como uma simples retórica, mas, sim, enquanto uma linguagem construída a partir de certas regras e interesses que podem ser desvendados.

Dessa forma, esse estudo tem como foco ressaltar a relevância de incorporar esse método de análise de maneira mais incisiva no âmbito das Relações Internacionais, especialmente por ser um espaço completamente permeado pela prática discursiva. Por isso, espera-se que os teóricos pós-positivistas possam inserir abordagens discursivas no referencial de análise, de forma desvencilhada das preocupações em torno da aceitação na área e das críticas das perspectivas positivistas.

Frise-se ainda que toda teoria consiste em um processo de formação pautado em interesses e em métodos. Na realidade, vale realçar a solidez do método da análise de discurso, desde que utilizado seguindo as premissas de Fairclough (2001, p. 100-101) e/ou Chouliaraki e Fairclough (1999, p. 60), ou seja, partindo de etapas concretas para problematizar determinado discurso. Logicamente, que as variantes temporais e os locais de onde são proferidos os discursos são sempre relevantes, além de, necessariamente, ser importante uma linha lógica que permeie a análise discursiva.

Assim, refletindo sobre o próprio ato de análise de discurso desse artigo, vê-se que se tentou realçar a possibilidade de o discurso de segurança humana estar em plena conexão com a política externa japonesa e a segurança nacional, reforçando-as de maneira implícita. Claro que essa percepção leva em consideração um olhar histórico e bibliográfico, reforçado pela análise discursiva e não, simplesmente, uma apresentação do conteúdo dos discursos, principalmente porque o estudo discursivo se encontra referendado pelas nuances das Relações Internacionais. Então, refletindo sobre o próprio ato de análise feito, observa-se que existem outras dimensões 
do discurso de segurança humana japonês, como bem foi apontado por Atanassova-Cornelis (2005); mas, à guisa de todo o aparato que se utilizou, percebe-se a probabilidade de que realmente a análise feita possua delineamentos concretos.

Por isso, a importância de que novos estudos sejam realizados, considerando as etapas determinantes da análise de discurso, com finalidade de se chegar a outras percepções e resultados, ou mesmo de confirmar os pontos depreendidos dos discursos, considerando as interpretações históricas e atuais das Relações Internacionais. Dessa maneira, embora a análise de discurso trabalhe com o ato da fala, que é pautado de interesses e relações de poder, não pode ser vista como um método fraco analiticamente; pois, pelo contrário, envolve pontos que outros métodos não poderiam alcançar. Portanto, toda teoria e método de análise têm suas limitações e, assim, ocorre também com a análise de discurso, porquanto a necessidade de se utilizar abordagens focadas em multimétodos.

\section{Referências}

AKAMI, T. 2006. In the Name of People: Welfare and Societal Security in Modern Japan and Beyond. In: Asian Perspective. Vol. 30, N¹, pp. 157-190.

ARAGUSUKU, J. A. S. 2010. Segurança humana na política externa japonesa. Disponível em:<http://www. seminariosociologiapolitica.ufpr.br/anais/GT04/Juliano\%20Akira\%20de\%20Souza\%20Aragusuku.pdf >. Acesso em: 02 dez. 2012.

ARAGASUKU, J. A. S. 2011. A assistência oficial ao desenvolvimento na política externa japonesa. $3^{0}$ Encontro Nacional da ABRI. 2011. Disponível em: < http://www.proceedings.scielo.br/scielo. php?pid=MSC0000000122011000200042\&script=sci_arttext >. Acesso em: 22 out. 2015.

ATANASSOVA-CORNELIS, E. 2005. Japan and the "Human Security" Debate: History, Norms and Proactive Foreign Policy. In: Graduate Journal of Asia Pacific Studies, 3:2, 2005, pp. 58-74.

B00TH, Ken. Security and Emancipation. Review of International Studies, Vol. 17, n 4, 1991, pp. 313-326.

BOSOLD, D.; WERTHES, S. 2005. Human Security in Practice: Canadian and Japanese Experiences. In: IPG I, pp. 84-101. Disponível em: <http://library.fes.de/pdf-files/id/ipg/02694.pdf>. Acesso em: 30 ago. 2013.

CAMARGO, J. F. 2011. Mídia e Relações Internacionais: lições da invasão do Iraque em 2003.

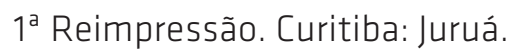

CHOULIARAKI, L.; FAIRCLOUGH, N. 1999. Discourse in Late Modernity. Rethinking Critical Discourse Analyses. Edinburgh: Edinburgh University Press.

CLAUSEN, D. 2009. Japan and Human Security - A Powerful Discourse or a Useful Coping Mechanism? In: Electronic Journal of Contemporary Japanese Studies, Discussion Paper 3. Disponivel em: <http://www. japanesestudies.org.uk/discussionpapers/2009/Clausen.html >. Acesso em: 01 set. 2013.

DER DERRIAN, James. The Boundaries of Knowledge and Power in International Relations. In: DER DERRIAN, James; SHAPIRO, Michael J. (Eds.). International Intertextual Relations - Postmodern Readings of Worlds Politics. New York: Lexington Books, 1999. 
DIETA NACIONAL. 1999. Discurso proferido na $145^{a}$ Sessão da Dieta Nacional pelo Primeiro-Ministro Keizo Obuchi em 19 jan. 1999. Disponivel em: <http://www.kantei.go.jp/foreign/souri/990121policy-speech. html >. Acesso em: 17 dez. 2012.

FAIRCLOUGH, N. 1996. Language and Power. London: Longman.

FAIRCLOUGH, N. 2001. Discurso e Mudança Social. Brasília: UNB.

FOUCAULT, M. 1986. A Arqueologia do Saber. Rio de Janeiro: Forense Universitária. 1996. A Ordem do Discurso. Aula Inaugural no Collège de France, Pronunciada em 2 de Dezembro de 1970. Trad. Laura Fraga de Almeida Sampaio. São Paulo: Edições Loyola. 2010. Microfísica do Poder. Org. e Trad. Roberto Machado. Rio de Janeiro: Edições Graal.

FUKUSHIMA, A. 2004. Human Security and Japanese Foreign Policy. In: Human Security in East Asia: International Conference in Human Security in East Asia. Disponivel em: <http://unesdoc.unesco.org/ images/0013/001365/136506e.pdf >. Acesso em: 13 dez. 2012.

GEORGE, J. 1994. Discourses of Global Politics: A Critical (Re) Introduction to International Relations. Colorado: Lynne Rienner Publishers.

GOMES, A. T. 2011. Análise de discurso e Relações Internacionais: duas abordagens. In: Revista Política Hoje, V. 20, N.2.

GONDIM, S. M. G.; FISCHER, T. 2009. In: Cadernos de Gestão Social, V. 2, N. 1.

HANSEN, Lene. Security as Practice: Discourse Analysis and the Bosnian War. London and New York: Routledge, 2006.

IKEDA, J. 2009. Creating the Human Security Discourse and the Role of Academic-Policy Complex: International Relations as Japanese Social Science? In: Interdisciplinary Information Sciences, Vol. 15, $N^{0} 2$, pp. 197-209.

MELO, I. F. de. 2009. Análise do Discurso e Análise Crítica do Discurso: Desdobramentos e Intersecções. In: Revista Eletrônica de Divulgação Científica em Língua Portuguesa, Linguística e Literatura. Ano 05, $n^{0} 11,2^{\circ}$ Semestre.

MILLIKEN, J. 2001. Discourse Study: Bringing Rigor to Critical Theory. In: FIERKE, K. M.; JORGENSEN, K. E. (Eds.). Constructing International Relations: the next generation. New York: M. E. Sharpe, pp. 136-159.

MUSSALIM, F. 2006. Análise de discurso. In: MUSSALIM, F.; BENTES, A. C. (orgs.). Introdução à linguística: domínios e fronteiras, vol.2. $5^{\text {a }}$ Ed. São Paulo: Cortez, pp. 101-142.

NIRANJANA, T. 1992. Siting Translation: History, Post-structuralism and the Colonial Context. California: University of California Press.

OLIVEIRA, A. B. 2009. O fim da Guerra Fria e os estudos de segurança internacional: o conceito de segurança humana. In: Aurora, ano III, n. 5, dez.

ONUF, N. 2002. Worlds of Our Making: The Strange Career of Constructivism in International Relations. In: Donald J. (Ed.). Visions of International Relations: Assessing an academic Field. Puchala. Columbia: University of South Carolina Press, pp. 119-141. 
ORGANIZAÇÃO DAS NAÇÕES UNIDAS. 2000. Discurso proferido na 55ª Sessão da Assembleia Geral das Nações Unidas pelo Primeiro-Ministro Yoshiro Mori. 7 set. 2000. Disponivel em: <http://daccess-dds-ny. un.org/doc/UNDOC/GEN/N00/634/35/PDF/N0063435.pdf?OpenElement>. Acesso em: 10 set. 2013.

2009. Discurso proferido na 64 ${ }^{a}$ Sessão da Assembleia Geral das Nações Unidas pelo PrimeiroMinistro Yukio Hatoyama. 24 set. 2009. Disponivel em: <http://www.kantei.go.jp/foreign/hatoyama/ statement/200909/ehat_0924c_e.html>. Acesso em: 17 dez. 2012.

2010. Discurso proferido na $65^{\text {a }}$ Sessão da Assembleia Geral das Nações Unidas pelo PrimeiroMinistro Naoto Kan. 24 de set. 2010. Disponivel em: <http://daccess-dds-ny.un.org/doc/UNDOC/GEN/ N10/549/59/PDF/N1054959.pdf?OpenElement>. Acesso em: 02 set. 2013.

2012. Discurso proferido na $67^{a}$ Sessão da Assembleia Geral das Nações Unidas pelo PrimeiroMinistro Yoshihiko Noda. 26 set. 2012. Disponivel em: <http://gadebate.un.org/sites/default/files/ gastatements/67/JP_en.pdf>. Acesso em: 17 dez. 2012.

ORLANDI, E. P. 2005. Michel Pêcheux e a Análise de Discurso. In: Estudos da Linguagem. Vitória da Conquista, n. 1, p. 9-13, jun.

PARIS, R. 2001. Human Security: Paradigm Shift or Hot Air? In: International Security. v. 26, n. 2, Fall, pp. 87-102.

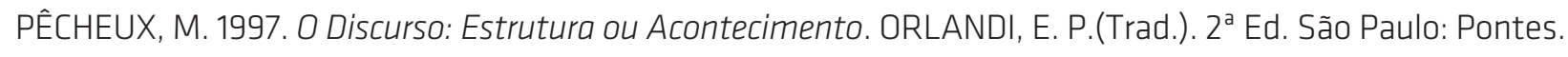
PÊCHEUX, M. 2007. Análise do discurso: apontamentos para uma história da noção-conceito de formação discursiva. GREGOLIN, M. R. (Trad.). São Carlos: Pedro\&João Editores.

PINTO, C. R. J. 2006. Elementos para uma análise de discurso político. In: Barbarói. Revista do Departamento de Ciências Humanas e do Departamento de Psicologia. N² 24, 2006/1, pp. 78-109.

PODER AÉREO. Disponível em: <http://www.aereo.jor.br/2015/09/19/forcas-de-autodefesa-do-japaoagora-podem-realizar-operacoes-militares-no-exterior/>. Acesso em: 22 out. 2015.

RESENDE, V. M.; RAMALHO, Viviane. 2006. Análise de Discurso Crítica. São Paulo: Contexto.

REVEL, J. 2005. Foucault: conceitos essenciais. GREGOLIN, M. R. et al. (Trad.). São Carlos: Claraluz Editora. SAKURAI, C. 2011. Os Japoneses. São Paulo: Contexto.

SEGURA, C. G. 2006-2007. Seguridad humana: conceptos, experiencias y propuestas. In: Revista CIDOB D'AFERS INTERNACIONALS, Nº 76, Dez. 2006- Jan.2007, pp. 79-95.

SHAPIRO, Michael J. Textualizing Global Politics. In: DER DERRIAN, James; SHAPIRO, Michael J. (Eds.). International Intertextual Relations - Postmodern Readings of Worlds Politics. New York: Lexington Books, 1999.

SUANO, M. J. F. 2005. O discurso teórico nas Relações Internacionais. In: Civitas. Porto Alegre, V. 5, № 2, jul.-dez., pp. 245-274.

TILIO, R. 2010. Revisitando a análise crítica do discurso: um instrumental teórico-metodológico. In: Revista do Curso de Letras da UNIABEU, Nilópolis,V. 1, N. 2, Maio-Ago., pp. 86-102.

ZEHFUSS, M. 2002. Constructivism in International Relations: The Politics of Reality. United Kingdom: Cambridge University Press. 